\title{
Development and evaluation of a telemedicine clinic service for CADASIL
}

\author{
Walsh J, Markus HS \\ Department of Clinical Neurosciences, University of Cambridge, UK
}

\section{Introduction}

Cerebral autosomal dominant arteriopathy with subcortical infarcts and leukoencephalopathy (CADASIL) is the most common form of hereditary stroke disorder. Key symptoms include stroke, cognitive decline, and migraine with aura. CADASIL is rare. This means than, as for many rare disorders, most effective care can be offered by specialist clinics, but a consequence of this is that patients may have to travel long distances to the clinic. This is the case for many patients attending the National CADASIL clinic at Cambridge (Figure 1). Therefore we explored other ways of providing this care and implemented a telemedicine service using Skype. However such Skype consultations could have challenges particularly for patients unfamiliar with technology and for those with cognitive impairment and disability. For this reason we carried out a formal evaluation and compared it to face-to-face consultations

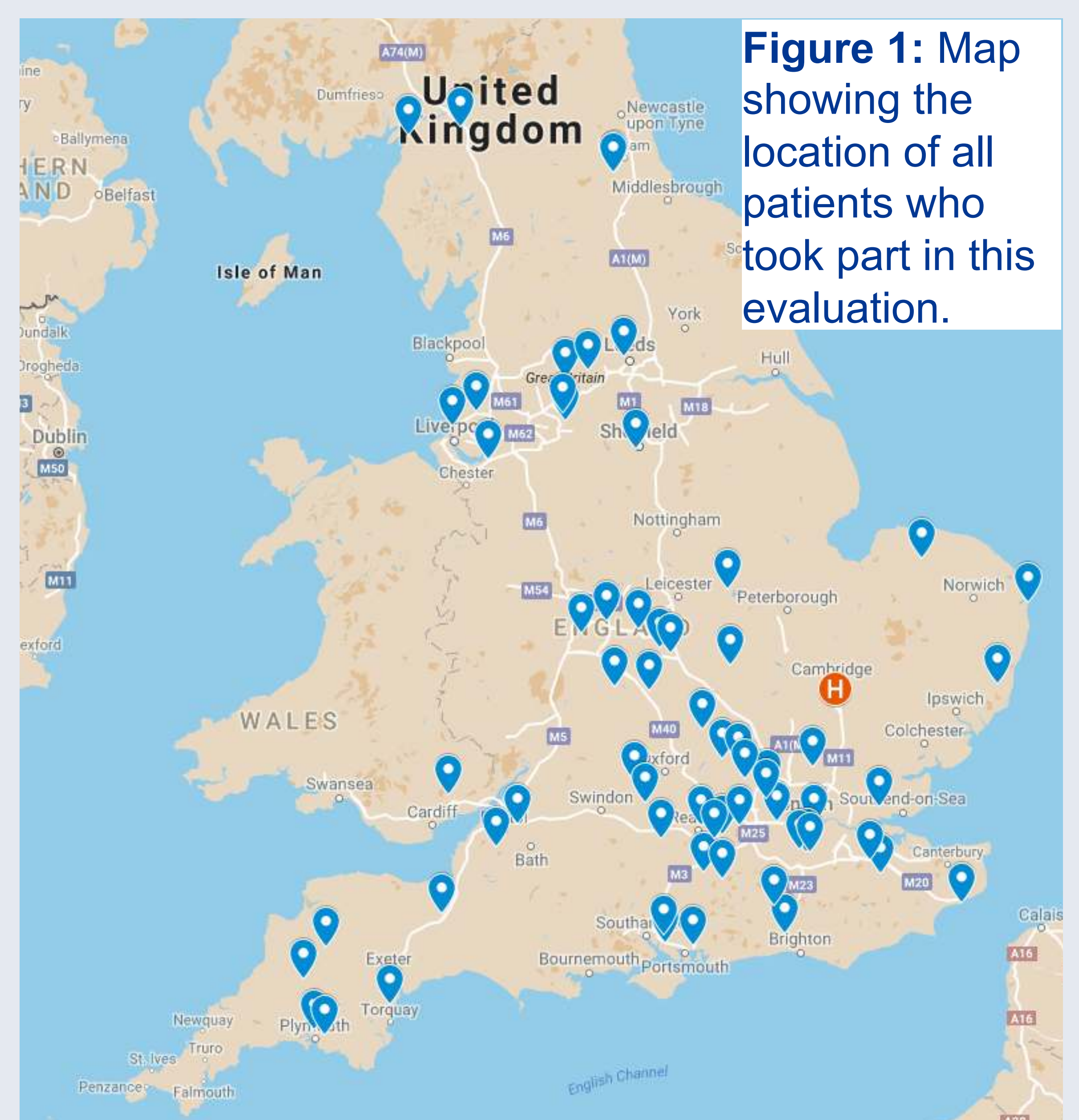

\section{Objectives}

- Compare patient and clinician experience of a telemedicine outpatient clinic service with that of a face-to-face service

- Compare the consultation length of a telemedicine outpatient clinic service with that of a face-to-face service

\section{Methods}

Participants: 64 telemedicine patients and 50 face-to-face patients, all undergoing a follow-up appointment, took part in this evaluation.

Time taken: The time taken from beginning of the consultation, to the clinician completing all paperwork for the patient was recorded.

Patient evaluation: Patients were asked to rate 12 statements from 'strongly agree' to 'strongly disagree'. An additional 5 statements were rated by telemedicine patients, evaluating the use of technology in the appointment.
Clinician evaluation: The clinician rated four statements from 'strongly agree' to 'strongly disagree'. Four additional statements were rated by the clinician for telemedicine appointments. The clinician indicated whether the patient had been diagnosed with dementia and rated them on the Modified Rankin Scale.

Depression and Anxiety Ratings: Patients were also asked to fill out the Hospital Anxiety and Depression scale (HADS) and the short form of the State-Trait Anxiety Inventory (STAI-6). These documented investigated depression and anxiety symptoms in the week prior to appointment and anxiety symptoms on the day, respectively.

\section{Results}

How long did the consultations take?

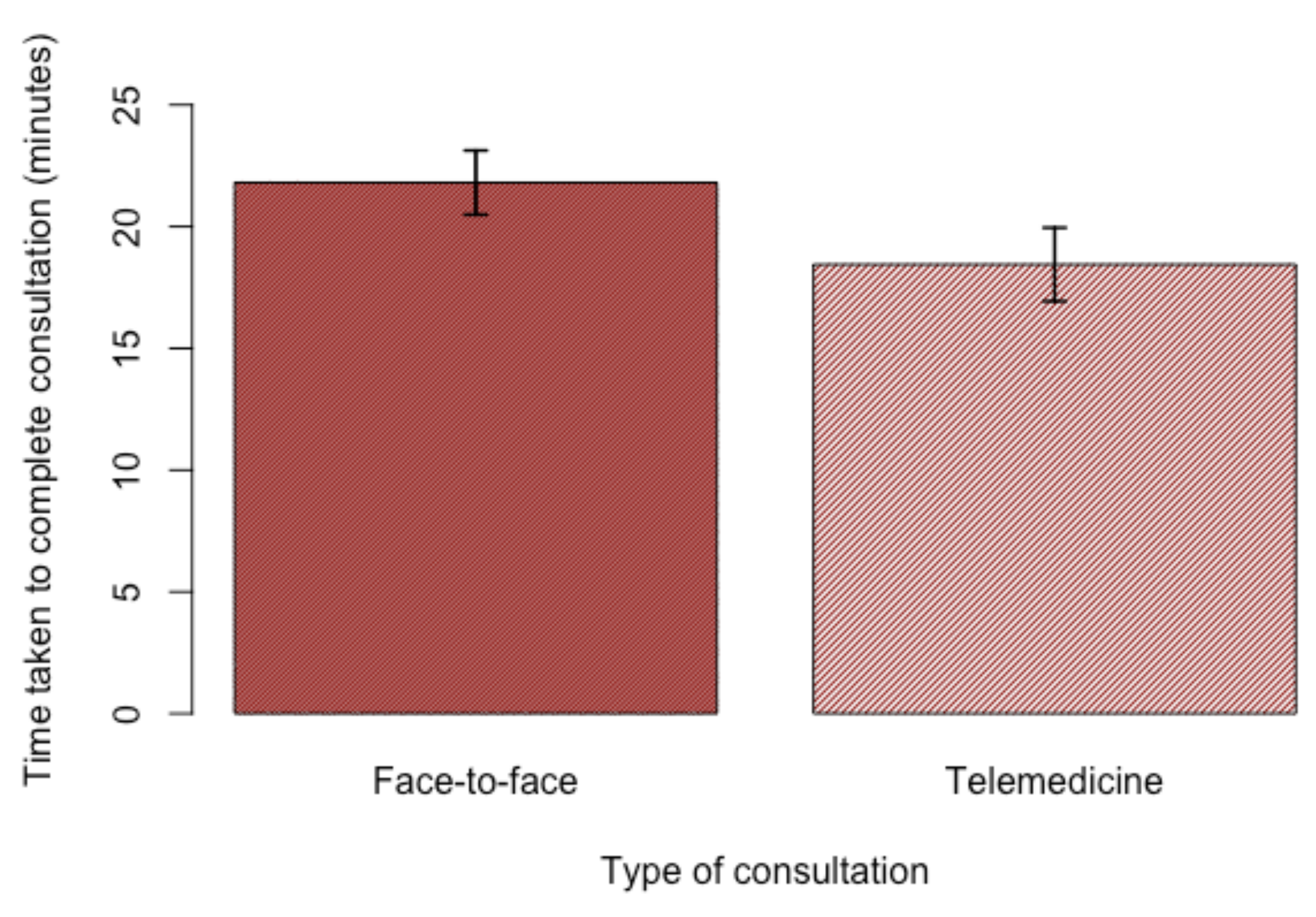

Figure 2: Telemedicine consultations took a significantly shorter amount of time than face-to-face consultations $(p=0.014)$. Error bars \pm 2 SEM.

How did the patient and clinician evaluate the consultations overall?
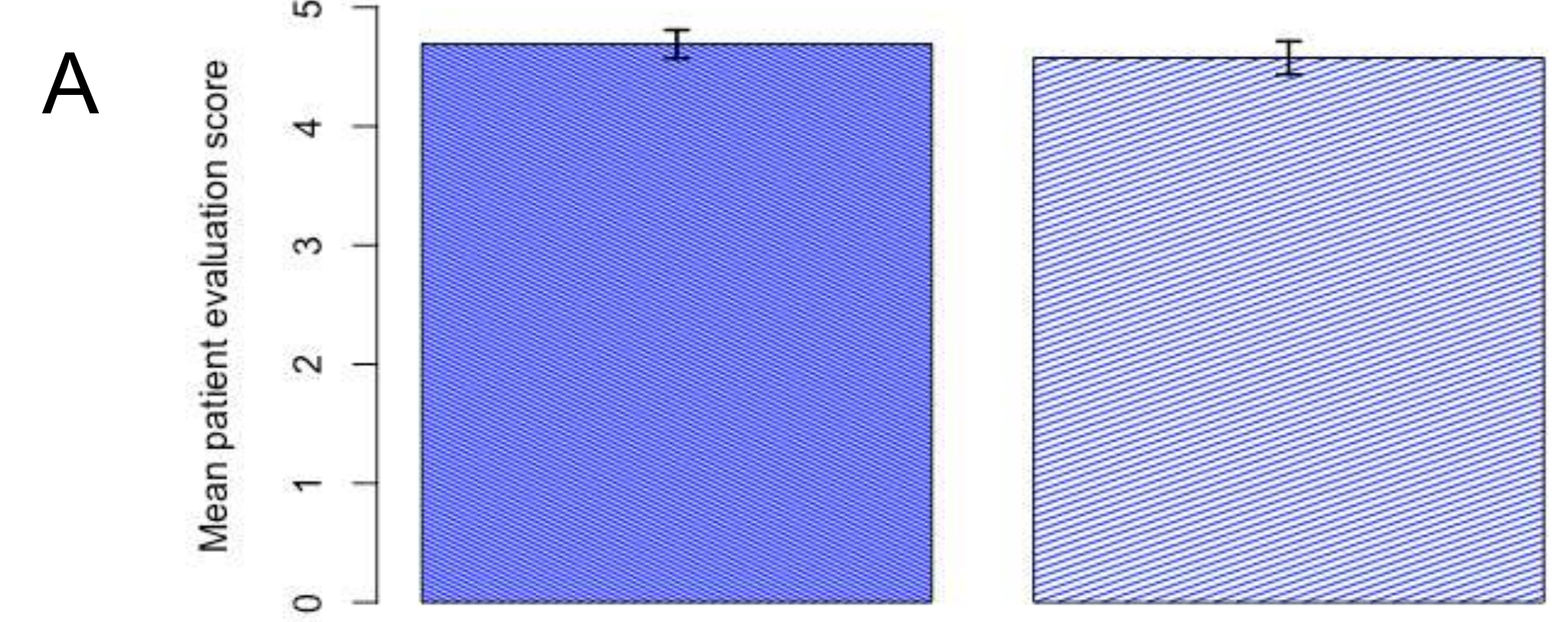

B
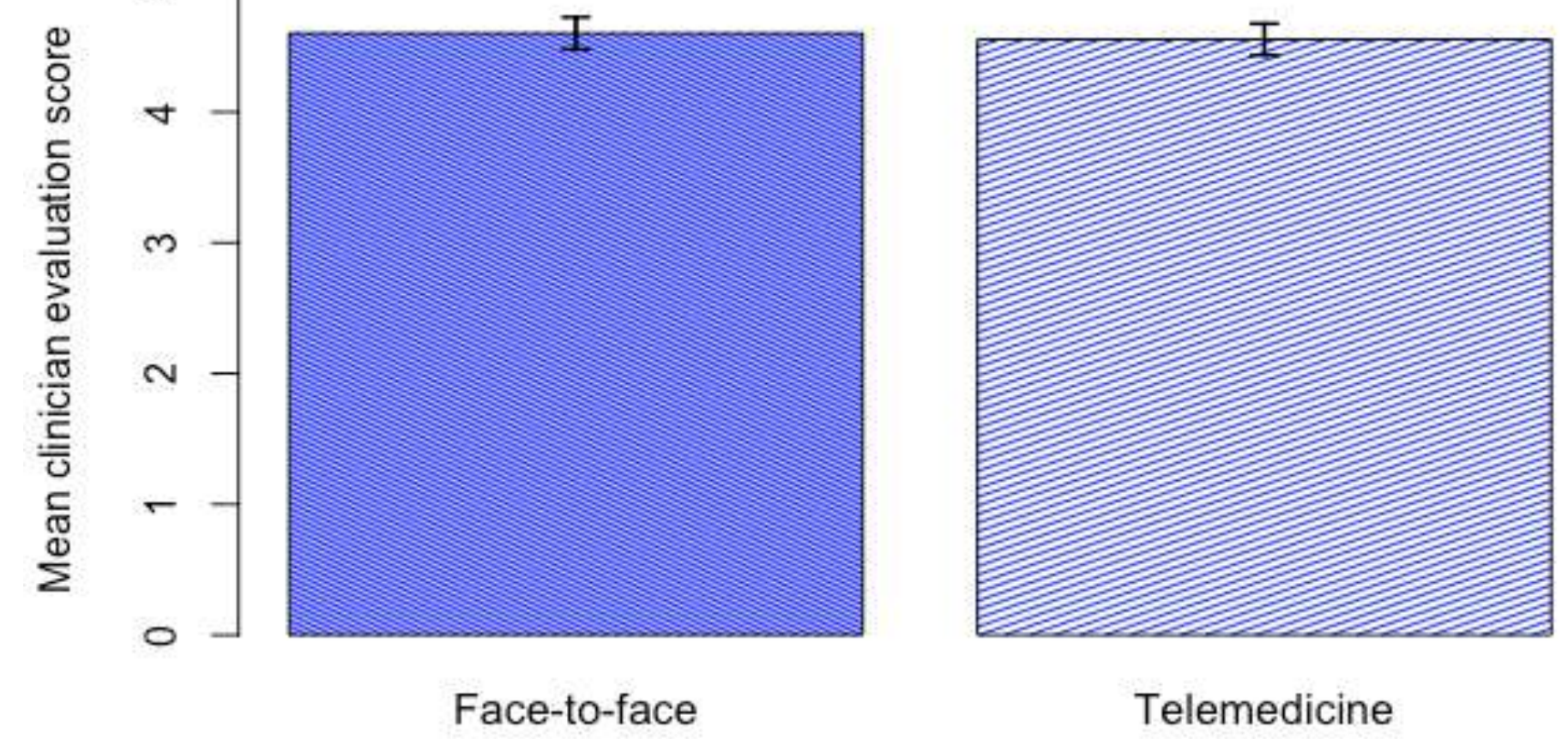

Figure 3: A) There was no difference between the mean patient evaluation score of face-to-face and telemedicine consultations $(p=1.00)$. B) There was no significant difference between the mean clinician evaluation score of face-to-face and telemedicine consultations $(p=0.44)$. Error bars \pm 2 SEM.

How much travel time was saved by the service?

$\begin{array}{cccl}\text { Round trip travel time (minutes) } & \begin{array}{l}\text { Table 1: Table } \\ \text { Interquartile } \\ \text { range }\end{array} & \begin{array}{l}\text { summarising the } \\ \text { average travel } \\ \text { time saved by this }\end{array} \\ 315 & 287 & 197 & \text { service. }\end{array}$

Did anxiety and depression scores differ between consultation type?

\begin{tabular}{lccc} 
& \multicolumn{3}{c}{ Face-to-face } \\
HADS Anxiety & $6.25(4.6)$ & $7.28(4.9)$ & 0.33 \\
HADS & $3.93(3.7)$ & $5.61(5.1)$ & 0.18 \\
Depression & $34.51(14.9)$ & $37.55(13.6)$ & 0.15
\end{tabular}

Table 2: No significant difference was seen in the HADS or STAI-6 scores between face-to-face and telemedicine groups.

\section{Did cognitive problems affect} satisfaction?

$\begin{array}{cccc}\begin{array}{c}\text { Appointment } \\ \text { type }\end{array} & \begin{array}{c}\text { Cognitive } \\ \text { problems }\end{array} & \begin{array}{c}\text { No cognitive } \\ \text { problems }\end{array} & \text { P value } \\ \text { Face-to-face } & 4.48(0.43) & 4.85(0.34) & <0.001 \\ \text { Telemedicine } & 4.22(0.63) & 4.79(0.35) & <0.001\end{array}$

Table 3: Patients with self reported cognitive problems had significantly lower satisfaction scores compared to those without for both face-to-face and telemedicine consultations.

Would patients use the service again?

$93 \%$ of patients who used the service said that they would like their next follow-up appointment to be via telemedicine.

\section{Discussion}

Telemedicine consultations took a significantly shorter amount of time in comparison to faceto-face consultations (Figure 2) by a mean of 3.4 minutes suggesting that it could be costsaving.

Patients and clinicians rated follow-up telemedicine consultations just as highly as face-to-face consultations (Figure 3), suggesting telemedicine calls are a useful service for patients and clinician.

There was no evidence that telemedicine consultations were associated with increased anxiety on the day of the appointment (Table 2). Patients with self-reported cognitive problems had significantly lower satisfaction scores for both telemedicine and face-to-face consultations (Table 3). This is something to be investigated to see if the service can be improved for those with cognitive problems.

Our data shows that the telemedicine service is useful for CADASIL patients and for the clinician. Based on this, telemedicine follow-up appointments are now offered in the routine NHS care for follow-up patients at the Cambridge CADASIL clinic. This may have implications for other clinics, where patients usually have to travel far to access the service.

This research was completed as a clinical audit at Addenbrooke's hospital, Cambridge. Audit number PRN4689. This project was generously funded by the Evelyn Trust. 